\title{
Europeanizing Universities: Expanding and Consolidating Networks of the Erasmus Mundus Joint Master Degree Programme (2004-2017)
}

\author{
Marcelo Marques ${ }^{\mathrm{a}, \mathrm{b}}$, Mike Zapp ${ }^{\mathrm{a}}$ and Justin J. W. Powell ${ }^{\mathrm{a}}$ \\ ${ }^{a}$ Institute of Education and Society, University of Luxembourg, Esch-sur-Alzette, Luxembourg. \\ E-mail: marquescmarcelo@gmail.com \\ ${ }^{\mathrm{b}}$ UIDEF, Instituto de Educação, Universidade de Lisboa, Lisbon, Portugal.
}

The Europeanization of higher education has gained considerable scope and momentum over the past quarter century. Whereas the coordinative Bologna process, with soft governance mechanisms, has facilitated standardization across countries, European Commission funding programs target universities more directly. The Erasmus Mundus Joint Degree Programme, as an incentive-based program, epitomizes the dynamics of such European funding management. Notably, it has established expanding university networks across Europe and unique new tertiary degrees that facilitate international student mobility. Applying social network analysis to 561 participating universities through several program cycles, we longitudinally examine three key patterns in the program's development: the expansion of the program, the consolidation of panEuropean networks, and the participation of and coordination by central universities in these Europeanization processes. Program participation increased considerably across cycles, even as established networks were consolidated, largely through re-accreditation of established programs. Moreover, we identify those universities that assume a central position in the inter-organizational structure of this international program. These universities actively facilitate the evolving Europeanization of higher education by strengthening inter-university networks via a signature EU program.

Higher Education Policy (2020). https://doi.org/10.1057/s41307-020-00192-Z

Keywords: Erasmus Mundus Programme; higher education; social network analysis; European funding management 


\section{Introduction: The EU's Growing Higher Education Portfolio}

The European Union's (EU) portfolio in higher education and research governance has grown considerably over the past quarter century. Growing student and staff mobility, the institutionalization of supranational research funding instruments, an increasing number of European academic journals, pan-European disciplinary associations, and university alliances as well as an elaborate bureaucratic architecture of quality assurance, accreditation, qualification frameworks, and degree recognition regulations add up to what has come to be called the European Higher Education Area (EHEA) (de Wit and Verhoeven, 2001; Blitz, 2003; van der Wende and Huisman, 2004; Barrett, 2017; Zapp and Ramirez, 2019). Most attention has been paid to the supranational Bologna process, and this is, due to media and scientific attention alike, often erroneously assumed to fully cover Europeanization dynamics in higher education. The European Union's active direct support of (and influence on) universities in research and teaching across national borders remains less visible. Thus, we aim to uncover how one signature program - The Erasmus Mundus Joint Degree Programme, as an incentive-based program - epitomizes the dynamics of such EU funding and management. It does so reflecting larger globalization processes that to some extent de-link the nation-state and public universities (Kwiek, 2006).

While the EU's growing role as an active promoter, coordinator, and governance body of transnational higher education mobility and collaborative science has been increasingly recognized, the EU's role as a direct and indirect manager of higher education and research governance and its impact on universities remains less well researched. Direct and indirect management, as opposed to shared management, refer to types of EU budget management that largely bypass member states (MS) via funding programs, even as these EU activities affect organizations within them. Funding programs impact and target universities more directly as they facilitate international networks, establish novel joint degrees, and drive cross-border exchange.

Thus, we argue that the Erasmus Mundus Joint Master Degree Programme (EM) is a highly relevant case of such European policy instruments that significantly influences developments at university level. Introduced in 2004 to promote excellence, the EM exemplifies the evolution of European higher education governance by creating clear incentives through funding programs (Marques, 2018; Zapp et al., 2018a, b) as it directly targets and supports universities and, crucially for a supranational government, inter-university networks that extend across national borders. The EM exemplifies Europeanization as it establishes a novel logic in how teaching should be organized and degrees conferred. This new logic involves the creation of European university networks as a distinct layer in an increasingly interconnected, and nested, global higher education field (Hüther and Krücken, 2016; Brankovic, 2018). 
While previous studies focus either on top-down European regulations or bottom-up processes led by academics, university managers, and students, we here highlight the macro-level and meso-level interplay between European funding initiatives and universities themselves. We argue that the rise of joint degrees over the past 15 years - exemplified here by the EM - is both an indicator of Europeanization of higher education and of universities' shift toward becoming explicitly European regional and global actors, transcending local and national levels.

Firstly, we review the literature on Europeanization in higher education and research governance, emphasizing the lack of attention that university influence within the 'European project' has received. Secondly, we compare direct and indirect as well as shared types of EU funding management, showing how the Erasmus Mundus Programme, as opposed to shared management between EU and national member states, integrates both direct and indirect types of management. Thirdly, we trace the EM in its development since 2004 and conceptualize this instrument as a case of Europeanization through the introduction of a new form of joint higher education degree and the creation of robust university networks. Then, we present our database and methods. Drawing on exhaustive data on EM joint degrees provided by the EU's Education, Audiovisual and Culture Executive Agency (EACEA) for the full program period of three cycles (2004-2017; $N=561$, we constructed a fit-for-purpose database. We apply social network analysis (SNA) to examine patterns of expansion and consolidation, especially relating to those universities that participate most, coordinate the most EM programs, and enjoy the highest 'degree centrality' — the leaders of such European university networks.

Our results emphasize three specific phenomena: (1) the expansion of joint degree programs; (2) the consolidation of networks across program cycles; and (3) the positioning of the most central universities in the expansion and consolidation of the EM. We find not only considerable expansion of joint degrees and participation but also clear patterns of consolidation through the cyclical reaccreditation of established programs. Further, a small group of organizations has influentially consolidated multiple such European teaching program networks, with these key universities taking on strong coordinative roles within and across different regions of Europe. A few key universities are active as the most central nodes across the entire network. These findings stress the crucial role of universities as drivers of Europeanization. Finally, we identify promising areas for further theorization and analysis. Among these, we emphasize EU-university relations and the importance of the university to the European project of regional integration. The present study contributes to a growing body of research that investigates Europeanization in higher education by highlighting universities as key actors that respond strategically to EU policies and programs. 


\section{Universities Europeanizing Higher Education?}

The concept of Europeanization has been an important theoretical tool to understand the relationship of European institutions with member states (MS) and its impact on domestic policies (Featherstone and Radaelli, 2003). Analyses of this emergent higher education governance architecture highlight mainly ideational and normative issues that permeate the construction of the Higher Education Research Area (Capano and Piattoni, 2011; Powell et al., 2012; Powell and Finger, 2013; Veiga and Magalhães, 2017). Other scholarship attends to drivers of change in European higher education, such as the Bologna Process, the European Credit Transfer and Accumulation System, the Open Method of Coordination or the European Qualifications Framework (de Wit, 2003; Maassen and Olsen, 2007; Amaral et al., 2009; Vukasovic, 2013; Dobbins and Knill, 2014; Curaj et al., 2015; Serrano-Velarde, 2015). While such scholarship unveils important aspects of Europeanization, we investigate here a related development that has thus far received little attention.

What impact does funding, provided by the European Commission directly to universities, have on cross-national program development in higher education? These university-targeted incentives mainly include funding instruments, such as mobility programs, that seek to directly impact European universities through support for and influence on their cross-border activities. Importantly, we note that universities have always been close to the center of European integration processes in general and to the creation of the European Higher Education Area (EHEA) in particular, especially regarding cross-border student mobility (Beech, 2019; Kmiotek-Meier et al., 2020). In fact, after the founding of the Council of Europe in The Hague (1948), the idea of a federation of European universities and the development of distinctly European (higher) education was discussed (de Wit and Verhoeven, 2001; Pépin, 2006). More recently, Risse (2010) directs attention to the role of universities in promoting general values of and attitudes toward European identity.

A quarter century later, the first European funding programs for student mobility (Action Programme, The Short Study Visits Scheme, COMETT, and ERASMUS, among others) were institutionalized, incrementally, in the portfolio of European cooperation activities. Therein, universities were crucial, as they participated in myriad European programs and influenced domestic policy change via providing expertise and platforms for dialogue. Examples include the establishment of international relations offices in universities (de Wit and Verhoeven, 2001), awareness of a country's European neighbors in higher education (Neave, 2005), the internationality of higher education and cross-border exchange in Europe (Altbach and Teichler, 2001; van der Wende and Huisman, 2004), or the legitimization of the Bologna reforms (Teichler, 2017). 
Despite these important contributions that identify universities as crucial actors in European integration, the establishment and development of networks of cooperation between universities to facilitate and strengthen supranational collaboration structures has largely remained a black box. Such emergent structures are, for example, found in teaching (EM) or in European research (e.g., the Marie Curie Joint PhD Programmes, the EU Framework Programmes, such as Horizon 2020, and, the European Research Council). Here, we focus on the relationship between the European Commission (EC) and individual universities and how the instrument of joint degree programs facilitates Europeanization. Next, we turn to the conceptualization of such EU-university relations through various management types of EU funding.

\section{Europeanizing Higher Education through Direct and Indirect Management Funding}

The EU's budget management is a crucial aspect in the implementation of its public policy, yet, as Lévy (2000) notes, while policy development, the European economy, or treaties of law are well-understood instruments in EU governance; more 'mundane' aspects like the operational management of programs have been largely ignored. Thus, this section highlights contrasting types of EU budget management and identifies where the Erasmus Mundus Joint Master Degree Programme (EM) fits, also within the EHEA.

Three different types - shared, direct, or indirect - constitute the EU's means of managing budgets. The major type of budget management refers to shared management and accounts for $76 \%$ of the total EU budget (European Parliament, 2019). This type comprises budgets entrusted to the Member States and is implemented nationally through further contracts with local companies or municipalities. This type is explicitly referred to in the European Treaty, which provides that 'the Commission shall implement the budget on its own responsibility in cooperation with the Member States' and that 'Member States shall cooperate with the Commission to ensure that the appropriations are used in accordance with the principles of sound financial management' (Article 317 TFEU) (DirectorateGeneral for Budget, 2018). Here, the Commission plays a supervisory role and the most common examples are the European Structural and Investment Funds. ${ }^{1}$

Direct management is defined as the direct implementation of budgets by the European Commission (EC) or related departments and executive agencies. Roughly, 22\% of the EU's budget is managed in this category (European Parliament, 2019). Concretely, this means that a fund or program is directly managed by the EC or one of its agencies. The management involves selecting contractors, awarding grants, transferring funds, monitoring activities, and others (Directorate-General for Budget, 2018). Examples of such EC-directed programs 
are the European Global Navigation Satellite Systems Agency or the tax-related Customs 2020 and Fiscalis 2020 initiatives (2014-2020).

The third type of European budget management is indirect and accounts for only $2 \%$ of the EU's budget (European Parliament, 2019). It is defined as the indirect implementation of the budget by entrusting budget-related tasks to entities and persons (Directorate-General for Budget, 2018). This implies the involvement of one or more third parties, such as third countries, international organizations, or the European Investment Bank Group, among others, with the aim to acquire expertise, to facilitate cooperation, or to enhance cost-efficiency.

In higher education and research, budget management is mainly organized directly or indirectly - or both. The Erasmus+ program, for example, is managed directly by the EC and the Education, Audiovisual, and Culture Executive Agency (EACEA) as well as indirectly through the national agencies in program countries and national offices in partner countries. While the EC is responsible for managing the budgets, setting priorities, identifying program targets and criteria, monitoring and guiding the implementation and providing follow-ups and program evaluations, EACEA is in charge of promoting the program, launching calls for proposals, reviewing grant proposals, contracting and monitoring projects and communicating the results.

While we argue that the actions of EC and EACEA have a large direct impact on universities, national agencies are also involved in the management of the program. Erasmus + national agencies and the national offices in partner countries are responsible for providing information on the program, reviewing applications as well as monitoring and evaluating the implementation of the program in their country, supporting people and organizations intending to participate, and promoting the program at local and national levels (European Commission, 2016). If EACEA manages 'centralized actions' of Erasmus+ (and EM programs within this portfolio), the latter national agencies manage 'decentralized actions' that are tailor-made at national level, in accord with national priorities and aims, while staying within the objectives of the European program.

The Erasmus Mundus Joint Master Degree Programme (EM) is organized, at present, under the Erasmus+ umbrella initiative, and does not imply any form of shared management between the EC and the MS. As a consequence, universities have significant autonomy in creating, maintaining, and expanding their collaborative networks. Such networks, incentivized by the EU and by universities themselves, have gradually established a distinctive layer in the process of Europeanization of higher education, namely a cross-national university network for joint (or double) degrees. How did the Erasmus Mundus Programme develop and what are its consequences for the ongoing Europeanization of higher education? We next turn to the evolution of this program since its foundation in 2004 and its implications for universities as well as national higher education systems. 
Marcelo Marques et al.

\section{Higher Education Europeanization: The Erasmus Mundus Joint Master Degree Programme}

Initiatives to promote student mobility have been at the core of European higher education governance since the beginning (de Wit and Verhoeven, 2001; Teichler, 2002; Papatsiba, 2006; Rivza and Teichler, 2007). Relatedly, joint degrees have also been on the agenda since the start of the Bologna Process (DGEC, 2016). However, only with the Erasmus Mundus Joint Master Degree Programme (EM) did universities become actively involved in the creation and elaboration of European degree programs (see Knight, 2008). In fact, a study conducted in 2007 reported that $60 \%$ of the surveyed universities have joint programs (Crosier, Purser and Smidt, 2007), while another study showed that $95 \%$ of the universities surveyed intended to develop joint or double degrees in the future (Obst et al., 2011). Increasingly, they do this with the support of the EM.

The EM was launched in 2004 and has had three funding cycles thus far: 2004-2008 (€230 million), 2009-2012 (€493 million), and 2013-2020 (approx. €1 billion), with its budget more than doubling each funding cycle. Promoted as a 'prestigious, integrated, international study program' (EACEA 2019), it aims to support the development of quality European Master's (and, through 2013, also doctoral) degrees and to promote the visibility and attractiveness of European higher education in non-member countries that have been eligible to become partners since the second cycle (2009-2013). In the period 2004-2015, the EM funded around 20,000 Master's scholarships and 1440 doctoral fellowships in 328 postgraduate programs (DGEC, 2016).

Despite large increases in investment, scholarships, post-graduation programs, and participating universities, the EM has received little attention from higher education scholars. The few available studies focus on issues of accreditation, employability, and students' experiences (DGEC, 2016; Balyasin et al., 2016). Studies find, for example, that the program promotes a European higher education brand, contributing to European identity and economic competitiveness (Papatsiba, 2014); the added value of specific Master's degrees (Armstrong, 2012); its impact on regional development (Sadecka, 2011); or the improvement of intercultural competences (Yarosh et al., 2018).

Yet, we know little about the program's effects on the behavior of participating organizations and their collaborations; here, we pursue this line of research. Which universities participate in this cross-border program and what do these new networks imply for changing inter-organizational relationships in higher education in Europe and beyond? This lack of attention is all the more surprising as research has begun to conceptualize universities as 'strategic actors' that increasingly recruit students internationally and are eager to find new opportunities to form networks and alliances at national, regional, and 
global levels to enhance their competitiveness (Mohrman et al., 2008; Gunn and Mintrom, 2013; Hüther and Krücken, 2016; Brankovic 2018). Universities increasingly resemble 'normal' or 'complete' organizations in that they seek, on the one hand, autonomy, while also committing themselves to a field where inter-organizational relationships have become the rule rather than the exception (Krücken and Meier, 2006; Musselin, 2009). Such an 'associational' or 'relational' turn at the university level reflects the general organizational behavior diagnosed in the ample literature on inter-organizational relationships in which such new inter-organizational forms as joint ventures, virtual organizations, meta-organizations all point to more fluid organizational boundaries and routinized associational structures (Ahrne and Brunsson, 2008; Mutch et al., 2006; Powell et al., 2005; see also contributions in Cropper et al., 2008).

In Europe, such associations and alliances include, for example, the Network of Universities from the Capitals of Europe (UNICA; *1990), the European University Association (EUA; *2001), or the League of European Research Universities (LERU; *2002). However, beyond representative (e.g., EUA), geographically defined (e.g., UNICA) or more prestige-based associations (e.g., LERU), the EM adds a novel feature to inter-university collaboration by establishing a shared, i.e., transnational, sovereignty in granting boundary-spanning degrees that are jointly recognized. Students graduating from EM study programs are entitled to receive either a joint degree (i.e., one single degree certificate issued on behalf of at least two higher education organizations within the consortium) or multiple degrees (e.g., two degree certificates issued by two participating members of the consortium). Such a program-based legislative logic is unprecedented and, we argue, makes the EM instrument a highly relevant case of Europeanization through the direct interaction of European programs and universities across the region. Future research could usefully chart the receipt of joint degrees and the European careers enabled by them.

By focusing our analysis on the organizations participating in the program (meso-level), we intend to fill a research gap between those studies that focus on top-down processes, driven mostly from the macro-level and that impact national policies (such as the Bologna Process), and those that focus on processes and effects at the micro-level of individual mobility (e.g., Erasmus Programme for Student Mobility). The aim of our study is to understand how universities contribute to the evolving process of Europeanization in higher education. More precisely, we uncover how the program has been received and consolidated by universities across the cycles and which universities are central nodes in the interorganizational structure promoted by the program. 
Marcelo Marques et al.

\section{Data and Methods}

We draw on data from the Education, Audiovisual and Culture Executive Agency (EACEA), which manages educational and cultural programs on behalf of the European Commission (EC). Data represents the entire range of the Erasmus Mundus Joint Master Degree Programme for all three completed cycles (2004-2008, 2004-2012, and 2004-2017). Until 2013, the program also included joint doctoral programs, which then became integrated into the Marie SkłodowskaCurie Actions. In order to assure maximum data validity, we limit our analysis to three full cycles of MA programs. It is also important to note that in the year 2013, program openings were halted, only to be reinitiated a year later. In a multi-month coding process, we created a dataset that links participating universities (both coordinating and partner organizations) organized within individual programs and linked these to starting years and country information. The final population of organizations comprises 561 universities.

We apply social network analysis (SNA) to this unique dataset. SNA has enjoyed growing popularity in higher education studies over the past decade to examine the increasingly complex relationships across multiple levels in the field (Shields, 2013; Birkholz and Shields, 2017; Viseu, 2017). Yet, while analyses on macro (countries) and micro levels (e.g., researchers and students) have been common in these studies, less attention has been paid to (inter-)organizational phenomena on meso level. Following calls by Lazega et al. (2008) and Bellotti (2012) for more attention to this level of analysis, we here address this gap by focusing on universities directly in order to uncover collaborative patterns among these organizations embedded in the European network of joint degree programs.

Our analyses revolve around the answering of three questions - about (1) expansion, (2) consolidation, and the (3) centrality of network nodes. For the analysis of expansion and consolidation, we apply measures to the entire network - network diameter, average path length, density and clustering coefficient while for the centrality of universities, we apply degree centrality of the nodes. We elaborate on these and present the related measures (see Table 1 for an overview).

Focusing on (1) expansion, we show the number of funded EM degrees, identify the represented countries, and trace the evolution across funding cycles. To do so, we apply two different measures to analyze the overall structure of the network network diameter and average path length. The network diameter refers to the shortest path between two actors. For example, if from one funding cycle to the next, the diameter of the network increases, one can conclude that the network is expanding, while if it decreases, the nodes in the network are relatively closer to one another (Prell, 2012). In contrast, average path length shows how close universities are to each other in terms of their connections via the EM program. A decreasing path length coefficient across cycles indicates that inter-university ties have become tighter. 
Turning to (2) network consolidation, we rely on a density measure described as 'the proportion of all possible ties that are actually presented' (Hanneman and Riddle, 2005). If the Erasmus Mundus network becomes denser across cycles, we assume that universities become more aware of other universities within the EM network, not only consolidating but also expanding their collaboration with other member universities already within the network. Moreover, the clustering coefficient measures the tendency of organizations to cluster together (Watts and Strogatz, 1998). This implies that an increase in the degree of clustering across EM funding cycles suggests that organizations tend to repeatedly participate and collaborate with the same organizations. Along with the density measure, it contributes to the understanding of consolidation dynamics in the network.

Finally, in order to identify the core organizational actors in this pan-European network, we apply degree centrality, i.e., the number of relationships a given university has within the network. This measure helps us to understand which universities play central roles within the network. Here, we not only look at the number of connections but also what universities actually do across cycles, whether as a simple partner of a consortium or as coordinator - or acting in both capacities. Universities that have coordinated at least one program were coded as coordinators, while universities that have never coordinated a program were coded as partners only. Such distinctions in the visualization of the network are important because they provide insights into the twofold network structure of universities that assume the coordinator role (organizations that submit the project proposal on behalf of all the partners) and those that merely assume partner roles. To improve visualization of these network relationships, the coordinator/partner binary code is represented by different colors of the node, while degree centrality is indicated by the size of the node. However, that does not mean that universities that are coded as coordinators do not assume partner roles. Because we are also interested in showing which universities have the highest number of EM participations, whether as

Table 1 Analytical framework

\begin{tabular}{|c|c|c|}
\hline $\begin{array}{l}\text { Analytical } \\
\text { category }\end{array}$ & Research questions; expectations & $\begin{array}{c}\text { Indicators and network } \\
\text { measures }\end{array}$ \\
\hline Expansion & $\begin{array}{l}\text { The EM network grows over time; } \\
\text { New European and non-European participants } \\
\text { join the network across cycles }\end{array}$ & $\begin{array}{l}\text { Number of participating } \\
\text { universities and countries } \\
\text { Network diameter } \\
\text { Average path length }\end{array}$ \\
\hline Consolidation & $\begin{array}{l}\text { Universities consolidate intra-network ties by re- } \\
\text { accrediting their programs }\end{array}$ & $\begin{array}{l}\text { Density } \\
\text { Clustering coefficient }\end{array}$ \\
\hline $\begin{array}{l}\text { Centrality of core } \\
\text { universities }\end{array}$ & $\begin{array}{l}\text { Some universities occupy more central positions } \\
\text { in the network; } \\
\text { Which universities are the most central nodes, } \\
\text { both as coordinators and partners? }\end{array}$ & Degree centrality \\
\hline
\end{tabular}


Marcelo Marques et al.

coordinators or partners, we also provide these data (not represented in the visualization) in tabular form.

In line with the assumptions from previous research and given the proactive EU policy to expand the EM program after 2009, including non-European partners, we expect overall expansion in university participation. More precisely, we expect to find an increase of the network diameter and the average path length between organizations.

Additionally, previous research shows that since building ties involves costs and trust-building, organizations tend to seek stable and long-term inter-organizational relationships, especially given the norm of universities being embedded in a growing associational structure and nested organizational fields (Powell et al., 2005; Hüther and Krücken, 2016; Brankovic, 2018). Therefore, we expect to find consolidation across (and within) organizations that is reflected in an increase in density and clustering.

Universities formalize and routinize project acquisition and management tasks and some universities do so more than others, which provides them with a comparative advantage vis-à-vis those that do not invest in such infrastructure. We expect that these specific universities constitute central nodes in the EM network and that they are key in continuously consolidating and expanding their ties reflected in growing degree centrality. In the following section, we present our findings organized around these three analytical categories.

\section{The Expansion and Consolidation of the Erasmus Mundus Programme Network and its Inter-organizational Structure}

In the analysis that follows, we first present patterns of expansion and consolidation of joint degree program partnerships, highlighting overall university participation and country participation numbers. We then identify the most central nodes in the Erasmus Mundus inter-organizational networks across the three cycles.

\section{Expansion and consolidation of joint degree programs}

Since the beginning of the program in 2004, the increase in European joint degrees has been impressive. With a short phase of stagnation in the years 2011-2013, the expansion of joint MA programs has been steady, with an average of 25 new programs starting every year (see Figure 1). In addition, we highlight a consolidation process through the re-accreditation of existing MA programs. Since 2008, 100 MA programs (28\%) have been funded at least twice and 27 have been funded more than twice (8\%). In total, $127 \mathrm{MA}$ programs have been funded at least twice (36\%), confirming continuous demand of interest in such programs by participants and the organizations that offer them. Especially with the potential 


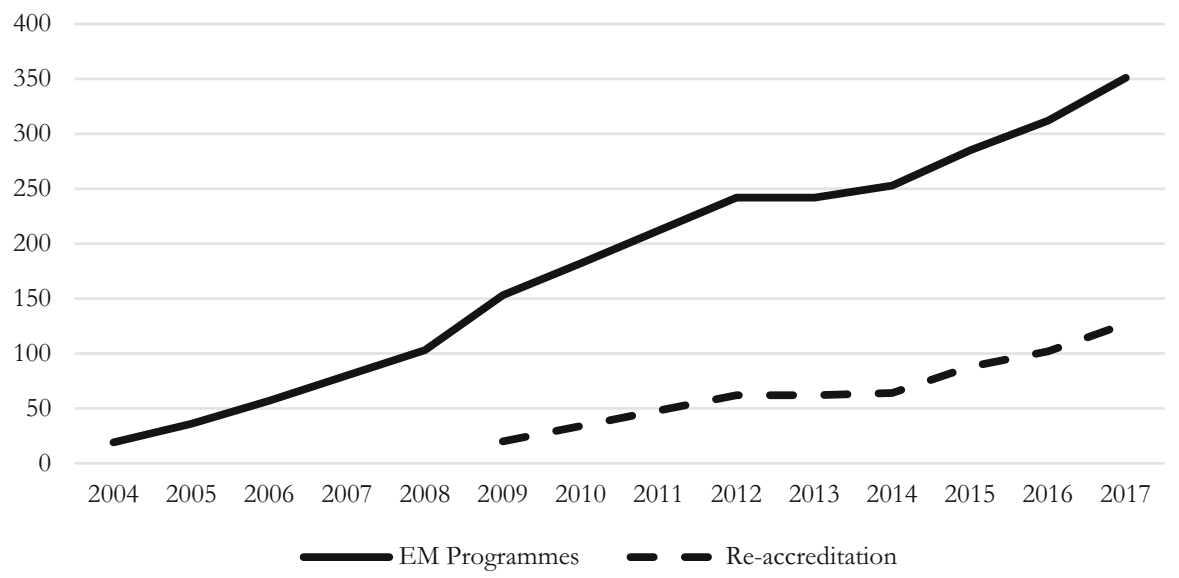

Figure 1. Erasmus Mundus Master Programme Expansion and Re-accreditation, 2004-2017. Authors' account based on EACEA 2017.

Table 2 Participating organizations in EM per country, top 10 countries' number and proportion of universities participating in EM by country.

\begin{tabular}{llcc}
\hline \multicolumn{1}{c}{ Country } & $n$ & \% EM programs & \% of universities in country participating in EM $^{*}$ \\
\hline France & 73 & 13 & 23.6 \\
Germany & 52 & 9 & 14.8 \\
UK & 41 & 7 & 23.7 \\
Italy & 40 & 7 & 40.8 \\
Spain & 40 & 7 & 36.7 \\
USA & 23 & 3 & n.a. \\
Portugal & 19 & 3 & 16.7 \\
Netherlands & 17 & 3 & 28.3 \\
Poland & 17 & 2 & 4.3 \\
Finland & 14 & & 37.8
\end{tabular}

Authors' account based on EACEA 2017 and WHEA 2018

* Share of participating universities by country is based on data from the International Association of Universities' World Higher Education Dataset (2018) and comprises universities offering at least a Bachelor's degree (3-4 years)

doubling $^{2}$ of funding in the next phase of Erasmus + (from 2021), both new EM programs and re-accreditations will very likely rise apace.

Looking at the most represented countries (Table 2), we observe that, as expected, the largest higher education systems in Europe account for almost half $(43 \%)$ of the total population of participating universities, with France $(13 \%)$ assuming the leading position, followed by Germany (9\%), the UK (7\%), Italy 
Marcelo Marques et al.

(7\%), and Spain (7\%). The USA is another top participating country in EM, building upon centuries-old traditions in academic exchange and, for two decades, EU funding for European Studies programs there.

Small- and medium-sized HE systems round out the top 10, with Portugal (3\%), the Netherlands (3\%), Poland (3\%), and Finland (2\%) representing notable proportions of EM participating organizations. Viewed in relation to the number of universities in each country, Italy, Finland, and Spain show the highest proportion of their universities participating in EM.

In order to explore such expansion and consolidation patterns more closely, we next analyze the composition of the network across the three funding cycles: 2004-2008, 2004-2012, and 2004-2017. Instead of treating each cycle as a separate network, we account for the dynamic evolution of these programs (i.e., the re-accreditation of existing partners and inclusion of new partners from one cycle to another) by analyzing the network cumulatively. We add new partners that join the inter-organizational structure from one cycle to another.

Table 3 displays common network measures of network diameter $(\varnothing)$, average path length $\left(l_{G}\right)$, density $(D)$, and clustering coefficient $(C)$. The first two measures confirm the EM program's expansion. The diameter of the network - the longest shortest path between two organizations - increased from $\varnothing=5$ to $\varnothing=7$ already between the first and second cycles, while the average path length - how closely related universities are to each another - has continuously increased from $l_{G}=2.847$ in the first cycle to $l_{G}=3.100$ in the last cycle. This shows that newcomers join the EM network at a steady rate. Such results must, at least partially, be viewed as organizational actors' reactions to the EC's strong encouragement to include partners from non-EU countries. In fact, while in the first cycle (2004-2008) only 18 organizations from 9 different non-EU countries were represented in the network, the following cycle (2009-2012) saw a huge increase to 126 organizations from 32 non-EU countries. Thus, the expansion occurs not only in the number of programs but also manifests internationalization as the network becomes more diverse in participating organizations and countries. Also due to the strong national higher education systems in Europe and the global influence of the Bologna process, the European Higher Education Area has become a model for other regions (e.g., Powell et al., 2012).

Table 3 Network measures of growth and consolidation in Erasmus Mundus programme (2004-2017).

\begin{tabular}{llll}
\hline & $2004-2009$ & $2004-2012$ & $2004-2017$ \\
\hline Network diameter $(\varnothing)$ & 5 & 7 & 7 \\
Average path length $\left(l_{\mathrm{G}}\right)$ & 2.847 & 3.032 & 3.10 \\
Density $(D)$ & 0.018 & 0.034 & 0.039 \\
Clustering coefficient $(C)$ & 0.585 & 0.688 & 0.713 \\
\hline
\end{tabular}

Authors' account. 
The density and the clustering coefficient measures also support the argument of consolidation among universities. Across cycles, the network becomes denser, with universities across programs becoming more aware of each other, indicated by increasing collaboration. While in the first funding period (2004-2008) the network density stood at $D=0.018$, the following cycles display measures of $D=0.034$ and $D=0.039$, respectively. In addition, the clustering coefficient measure reflects universities' tendency to strengthen their collaborative ventures since there is a steady increase across cycles: $C=0.585$ (2004-2008), $C=0.688$ (2004-2013), and $C=0.713$ (2004-2017). Such an increase may be explained by the reaccreditation of existing MA programs and by the inclusion of new partners in

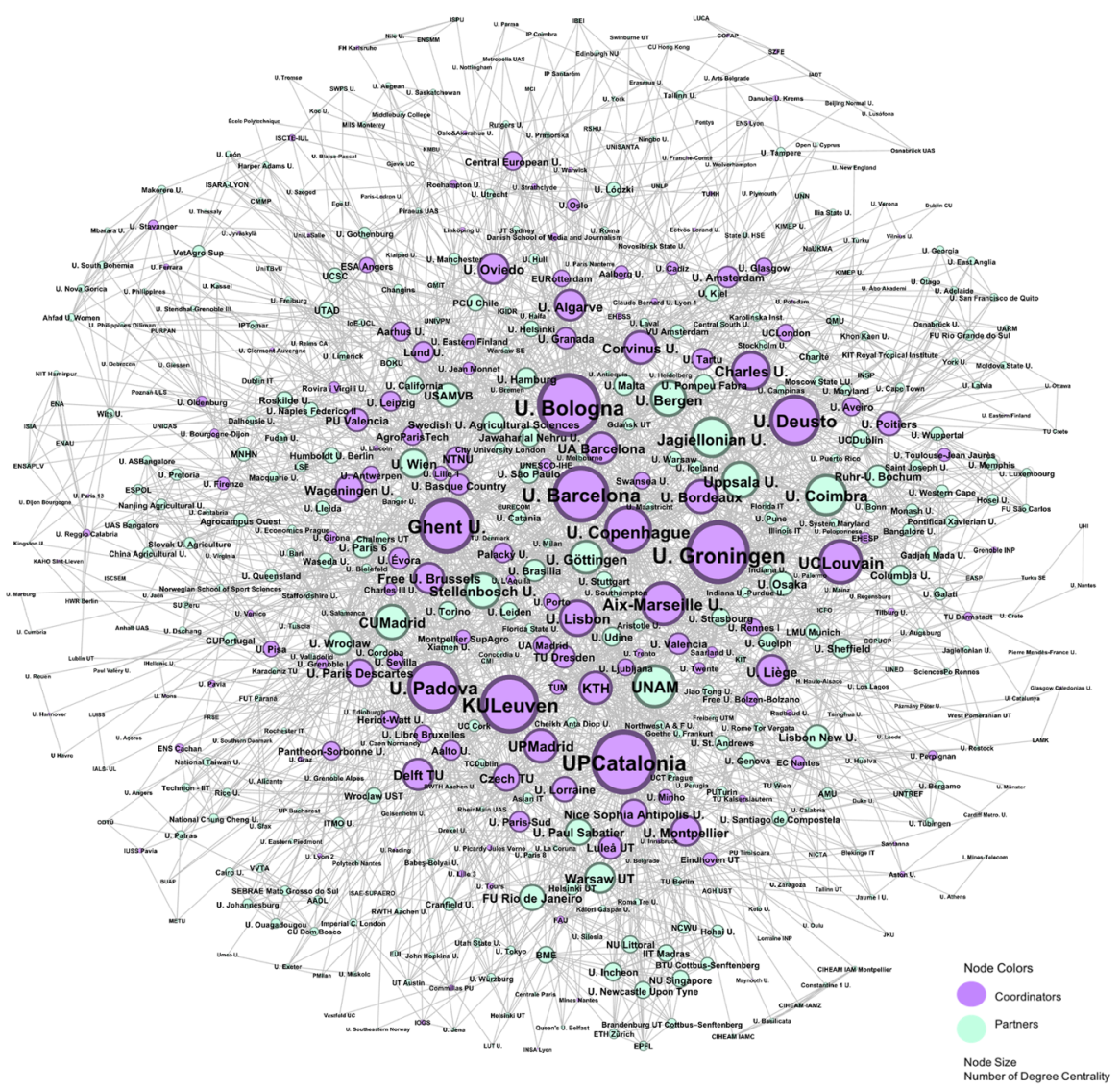

Figure 2. Degree centrality and role of universities in the EM network (2004-2017). Authors' account. 
Marcelo Marques et al.

already established program networks (with both European and non-European partners).

Expansion and increased density notwithstanding, some universities assume more central roles in constituting the inter-organizational structure of the EM program. We now look at these central university nodes around which the EM network, to a certain extent, revolves.

\section{Which universities have become central in the development of the Erasmus Mundus network?}

Figure 2 provides an overview of the degree centrality of universities (node size) and their role as either program coordinator and/or partners (node color).

Here, of many, we emphasize two findings. The most central universities have served at least once as an EM program coordinator, such as UBologna (Italy), UPCatalonia (Spain), UGroningen (The Netherlands), or KULeuven and UGhent (Belgium). Other universities are also key, but they have not yet assumed coordination roles, such as UNAM (Mexico), UCoimbra (Portugal), UUppsala (Sweden), UGöttingen (Germany), JagellonianU (Poland), UBergen (Norway), UStellenbosch (South Africa), and CUMadrid (Spain). Moreover, we also observe dozens of peripheral universities — in many countries — that do participate, yet are far from the center of the network.

To analyze those universities that indeed play the most central roles within this network, the above results are complemented by the 'degree centrality measure $\left(C_{D}\right)$,' i.e., the number of connections of the network's 10 most central universities (see Table 3). Overall, we observe that all of these universities have clearly developed capacity over time, institutionalizing their international MA programs via many participations in the EM, by coordinating numerous EM programs, and indeed doing so in collaboration with the most influential, well-connected universities in the network. These universities have been crucial in the development of the EM network across Europe and beyond. For example, our analysis shows that UPCatalonia $\left(C_{D}=122\right.$; Spain) is the most central university, and it has attained this highest number of participations through the establishment of a wide range of MA programs in many fields. By contrast, UGhent $\left(C_{D}=105\right)$ and KULeuven $\left(C_{D}=110\right)$, both in Belgium's community of Flanders, where higher education policy for decades has emphasized internationalization, achieve both high participation rates and are the most active coordinators. While these universities are leading coordinators, other universities must also be considered central nodes in the EM network: UGroningen (The Netherlands) coordinates 8 programs, UBordeaux (France) 7, UCopenhagen (Denmark) and UOviedo (Portugal) 6 each, while KTH (Royal Institute of Technology in Stockholm, Sweden), UPantheon-Sorbonne (France), USaarland (Germany), and UDeusto (Spain) have 5 each. These mainly public research universities form the backbone of the EM 
program. This shows the dominance of Western and Southern European and Nordic universities in leading a large number of MA programs. The strength of two Nordic and two Southern European organizations may well be related to these universities' organizational capacities in coordinating EM MA programs. Thus, the expectation that large, dominant higher education systems would have the strongest universities in the EM network cannot be confirmed; rather, smaller countries with strong and highly internationalized universities have also contributed to the successful institutionalization of the EM network.

Turning to the total number of EM participations (as coordinator or partner), UPCatalonia (24, Spain), UPadova (22, Italy) and Bologna (21, Italy) have participated in more than twenty different MA programs over the past 15 years, which shows how actively involved these universities are in the Europeanization of joint and double degrees. They are followed by UGroningen, UGhent and KULeuven with 18 participations each, UABarcelona with $16, \mathrm{KTH}$ with 15 , and UCopenhagen and UBarcelona with 14 participations each.

Finally, we present degree centrality as a measure of how central particular nodes are in the overall network (right-hand column in Table 4). The list of the most central universities reveals some important differences compared to the other descriptive quantitative indicators, as the simple number of participations does not necessarily reflect these universities' degree centrality. Although UPCatalonia is the university that gathers the highest number of EM participations and, at the same time, is the most central university in the network, this is not the case for UPadova, UGhent, or UCopenhagen. These universities are also heavily involved, yet, overall, their number of corresponding MA programs is smaller. Significantly, the most central universities in the EM network are geographically spread across Europe. Spain is the only country with three leading universities: UPCatalonia (116), UBarcelona (107), and UDeusto (96). Italy is represented at the top by two

Table 4 Erasmus Mundus university network coordination, total EM participations, and degree centrality (2004-2017).

\begin{tabular}{|c|c|c|c|c|c|c|c|}
\hline \multicolumn{2}{|l|}{ Coordination } & \multicolumn{2}{|c|}{ Total EM participations } & \multirow{2}{*}{$\frac{C}{4}$} & \multirow{2}{*}{$\frac{P}{20}$} & \multicolumn{2}{|c|}{ Degree centrality } \\
\hline Ghent & 13 & UPCatalonia & 24 & & & UPCatalonia & 122 \\
\hline KULeuven & 10 & Padova & 22 & 2 & 20 & Bologna & 120 \\
\hline Groningen & 8 & Bologna & 21 & 4 & 17 & Groningen & 119 \\
\hline Bordeaux & 7 & Groningen & 18 & 8 & 10 & KULeuven & 110 \\
\hline Copenhagen & 6 & Ghent & 18 & 13 & 5 & UBarcelona & 107 \\
\hline Oviedo & 6 & KULeuven & 18 & 10 & 8 & Ghent & 105 \\
\hline KTH & 5 & UABarcelona & 16 & 1 & 10 & Padova & 101 \\
\hline Pantheon-Sorbonne & 5 & KTH & 15 & 5 & 10 & Deusto & 96 \\
\hline Saarland & 5 & Copenhagen & 14 & 6 & 8 & Copenhagen & 90 \\
\hline Deusto & 5 & Barcelona & 14 & 1 & 13 & Aix-Marseille & 85 \\
\hline
\end{tabular}

Authors' account. 
ancient universities: UBologna (120) and UPadova (101). The Netherlands' UGroningen (119) is the third most central university in the EM network. The two strong and highly internationalized Flemish universities - KULeuven (110) and UGhent (105) - are also very central. Rounding out this group of key networked organizations are UCopenhagen (90) and the Mediterranean French university UAix-Marseille (85). Having presented the main findings and indicators, we turn now to a discussion of universities as Europeanizers providing crucial links across national borders and ensuring continuous collaboration between organizations and across scientific communities.

\section{Discussion: Universities as Europeanizers?}

The study of the evolving Europeanization of higher education has been focused on the governance architecture of the European Union as well as on the relationship between the EU and member states. Given that education has been a highly guarded and largely autonomous domain of EU member states, EU-level policies were crowded out. Yet since the Lisbon strategy (European Council 2003) and through the development of the intergovernmental Bologna Process, since 1998/1999 overarching goals and norms in European higher education have come to the fore (Curaj et al., 2015; Barrett, 2017). The Bologna Process influenced national and local decision makers to induce considerable reforms in higher education systems and individual universities, exemplifying how the European level has had influence even on those organizations supposedly shielded from external influence. (Of course, universities have always been organizations embedded in global communication and development.) As an initiative launched and funded at the European level, the EM program is more direct in incentivizing inter-organizational and international developments that require intercultural, cross-border collaboration. Here, we have emphasized a novel phenomenon of multi-level Europeanization in higher education that highlights the growing relationship between the European Commission and universities through direct and indirect management initiatives (see also Lévy, 2000).

As an important example of such management, the Erasmus Mundus programme represents the EU's ambition to incentivize university linkages within Europe and beyond, more selective (and concentrated) student mobility, and to introduce a new logic of conferring transnational degrees — that all undergird European ideals of exchange and mobility and facilitate the construction of European identity in and through higher education (Papatsiba, 2006; Risse, 2010). Our study identifies clear patterns of expansion and consolidation. We confirm a gradual expansion of MA programs and the Europeanizing role of participating universities embedded in larger and smaller European higher education systems, including Spain, Italy, 
Belgium (Flanders), Portugal, and, to a lesser extent, the Netherlands, France, Denmark, Sweden, and Germany.

We find that not only are many newly established cross-border MA programs being funded but also that a considerable number of MA programs seek reaccreditation to continue building pan-European bridges between organizations and individuals. Considering that the funding for EM is mainly distributed to supply student scholarships and that universities only receive a small amount for coordination costs, the results of continuous expansion and consolidation show the symbolic strength of the European project (and indeed the powerful pull of globalization) in higher education analyzed here through the relationship between funding instruments and the universities that educate each new generation of boundary-spanners. The presented social network analysis measures of network diameter and average path length support our expectation of continuous expansion through the continuous recruitment of newcomers, explicitly even those outside Europe - an explicit goal of the EM program. We also witness that consolidation occurs via older collaborations that attract new partners. This is especially the case with universities outside of Europe that, since 2009, have been encouraged to participate in the EM, thus contributing to the ongoing internationalization of European higher education policy (van der Wende and Huisman, 2004; Papatsiba, 2014). Notably, twenty-three US-based organizations are involved in collaborations with European organizations, which shows the strength of these ties in contemporary times and the motivation of many European universities to collaborate with American universities, reflecting US-European relations and the continuous transatlantic diffusion of ideas (Powell et al., 2012).

Summarizing, we confirm the steady institutionalization of the Erasmus Mundus Programme within the European Higher Education Area over the past quarter century. This finding supports recent arguments that contemporary universities are increasingly eager to collaborate, and as organizational actors they establish lasting networks across national political and cultural boundaries, which adds a more selective layer of student mobility to the general development of Erasmus+ (Rivza and Teichler, 2007; Brankovic, 2018; Marques, 2018). Universities create high demand for such European programs and renew their partnerships despite the oftensteep barriers of such participation, from the challenging maintenance of international collaborative networks, selectivity in proposals to the EC, or administrative burdens within the organization. While we find expansion and consolidation across the entire network, a small group of universities assuming the leading roles in developing these dynamic inter-organizational relationships. Degree centrality measures show how particular universities expand the scope of their action, both in terms of participation and coordination activities, but also with regard to strategic partnerships with other leading organizations within the EM network. These universities, from Barcelona to Copenhagen, account for the highest number of program participations and coordinate most EM joint degrees, 
which places them at the core of the EM program, where they contribute to panEuropean educational and scientific networks.

In relation to supranational funding instruments enabling the capacity for universities to expand the scope of their activities and in facilitating internationalization and intercultural exchange, the central role of the key EM universities is striking; this opens avenues for further research. To what extent and how do these universities act as drivers of Europeanization in higher education? Previous research on university networks has identified an 'internationalist' type of university with multiple international university association memberships, an internationalized curriculum, and a formalized organizational structure in charge of internationalization. How do these organizational and other factors, such as individual leaders or national policymaking, contribute to their capacity to participate across academic fields and coordinate numerous cross-border MA programs? How do these universities influence national policy change regarding cross-border accreditation and diploma recognition, also in weaving elite panEuropean networks among the highly educated? Such questions challenge the dominant top-down narrative in the Europeanization literature. They bring to the forefront the perspective of universities as strategic organizational actors that directly interact with the European Union as they build capacity to affect change at the national and local levels, through the reform of degree recognition legislation and other initiatives deriving from the successful networking supported by relatively modest funding from the European Commission.

Our results encourage further theorization and empirical investigation of these questions and direct attention to the relationship between European funding instruments and universities in order to enlarge the scope of Europeanization as the European Higher Education and Research Area gains further momentum.

\section{Conclusion}

This analysis focused on the European Union's Erasmus Mundus Joint Master Degree Programme (EM) as a driver of international collaboration in European higher education. The EM achieves the goal of Europeanization through direct and indirect management of funding instruments that support universities to establish cross-border MA programs. Funded by the European Commission, these programs establish joint degrees as a novel European feature in higher education that emphasizes international student mobility and academic networking, collaboration, and coordination. The EM incentivizes the creation of inter-organizational networks among European universities as well as with those outside the EU, often in the USA. The results of our longitudinal social network analysis of the Erasmus Mundus Programme demonstrate the steady rise of joint MA study programs over the period 2004-2017. Across the first three cycles, the number of MA programs 
established has grown to 351 programs. The number of participating universities grew from 483 to 1779 in the third cycle. These universities are based in important larger and mid-sized higher education and science systems, such as Spain and Italy, Belgium and Denmark as well as the USA as the main non-EU country partner. The network analysis also shows that the Erasmus Mundus network is led by a group of central and highly connected universities. These organizations not only account for the highest number of participations and coordinating roles in the EM, but are also well-connected to other highly Europeanized universities. These 'program hubs' continuously expand and consolidate their program partners in Europe and beyond.

This study identified important actors on multiple levels in the ongoing processes of Europeanization of higher education. To some extent bypassing national regulations and funding systems, organizations directly benefit from incentives to facilitate the EC's objectives of fostering pan-European networks in teaching across diverse academic fields while establishing a new, transnational, logic of degree conferral and recognition. Further research would evaluate the sustainability of such degree programs beyond EU support and also provide indepth meso-level case studies that reveal organizational, disciplinary, and individual leadership characteristics. These features enable certain universities not always the most well-known or top-ranked - to succeed as organizational actors as they avail themselves of the integration and network opportunities in graduate-level teaching provided by European Union programs designed to bolster the European Higher Education Area. Thus, the EU has strengthened the scope of its influence across levels, supporting organizations to extend their cross-border activities not only in research but also in teaching.

\section{Compliance with Ethical Standards}

Conflict of interest On behalf of all authors, the corresponding author states that there are no conflicts of interest.

\section{Notes}

1 The European Structural and Investment Funds aims at implementing consistently the five European funds such as the European Regional Development Fund, the European Social Fund, the Cohesion Fund, the European Agricultural Fund for Rural Development, and the European Maritime and Fisheries Fund.

2 The Erasmus+ programme for 2021-2027 has yet to be approved. While the EC has proposed the doubling and the European Parliament the tripling of funds, this will be finally decided by member states in the Council, together with the EP, as part of the Multi-annual Financial Framework (MFF) negotiations. 


\section{References}

Ahrne, G. and Brunsson, N. (2008) Meta-Organizations, Cheltenham: Edward Elgar.

Altbach, P.G. and Teichler, U. (2001) 'Internationalization and exchanges in a globalized university', Journal of Studies in International Education 5(1): 5-25.

Amaral, A., Neave, G., Musselin, C. and Maassen, P. (2009) European Integration and the Governance of Higher Education and Research, Dordrecht: Springer.

Armstrong, A.C. (2012) 'Collaboration, partnerships and alliances: Perspectives on Erasmus Mundus MA/Magister in special education needs', International Journal of Inclusive Education 17(4): 364-376.

Balyasin, M., Carvalho, L. and Mihut, G. (2016) 'Student experience: A new approach to evaluating the quality of Erasmus Mundus Joint Master Degrees through survey research', Educational Studies Moscow (1): 110-127.

Barrett, B. (2017) Globalization and Change in Higher Education. The Political Economy of Policy Reform in Europe, Basingstoke: Palgrave Macmillan.

Beech, S. (2019) The Geographies of International Student Mobility, Basingstoke: Palgrave Macmillan.

Bellotti, E. (2012) 'Getting funded. Multi-level network of physicists in Italy', Social Networks 34(2): 215-229.

Birkholz, J.M. and Shields, R. (2017) 'The Network Paradigm in Higher Education', in J. Huisman and M. Tight (eds). Theory and Method in Higher Education, Bingley: Emerald Publishing, pp. 215-226.

Blitz, B. (2003) 'From Monnet to Delors: educational cooperation in the EU', Contemporary European History 12(2): 197-212.

Brankovic, J. (2018) 'How Do Meta-Organizations Affect Extra-Organizational Boundaries? The Case of University Associations', in L. Ringel, P. Hiller and C. Zietsma (eds). Towards Permeable Boundaries of Organizations?, Bingley: Emerald, pp. 259-281.

Capano, G. and Piattoni, S. (2011) 'From Bologna to Lisbon: The political uses of the Lisbon 'script' in European higher education policy', Journal of European Public Policy 18(4): 584-606.

Cropper, S., Ebers, M., Huxham, C. and Ring, P.S. (2008) The Oxford Handbook of Inter-Organizational Relations, Oxford: Oxford University Press.

Crosier, D., Puser, L. and Smidt, H. (2007) Trends V: Universities Shaping the European Higher Education Area, Brussels: European University Association.

Curaj, A., Matei, L., Pricopie, R., Salmi, J. and Scott, P. (Eds.) (2015) The European Higher Education Area. Between Critical Reflections and Future Policies, Dordrecht: Springer.

de Wit, K. (2003) 'The consequences of European integration for higher education', Higher Education Policy 16(2): 161-178.

de Wit, K. and Verhoeven, J.C. (2001) 'The higher education policy of the European Union. With or against the member states?‘, in J. Huisman, J.P. Maassen and G. Neave (eds). Higher Education and the Nation State, Oxford: Pergamon Press, pp. 194-250.

Directorate-General for Budget (2018) Financial Regulation, Luxembourg: Publications Office of the European Union.

Directorate-General for Education and Culture (DGEC) (2016) Erasmus Mundus Joint Master Degrees. The Story So Far, Luxembourg: Publications Office of the European Union.

Dobbins, M. and Knill, C. (2014) Higher Education Governance and Policy Change in Western Europe, London: Palgrave Macmillan.

European Commission (2016) 2017 Annual Work Programme for the Implementation of 'Erasmus+'. C (2016)5571. https://ec.europa.eu/info/sites/info/files/file_import/Annual_work_programme_2017_ Implementation_of_Erasmus\%2B_C\%282016\%295571_en_0.pdf. Accessed 27 January 2019.

European Parliament (2019) Implementation of the Budget. http://www.europarl.europa.eu/factsheets/en/ sheet/30/implementation-of-the-budget. Accessed 23 January 2019. 
Featherstone, K. and Radaelli, C. (eds) (2003) The Politics of Europeanization, Oxford: Oxford University Press.

Gunn, A. and Mintrom, M. (2013) 'Global university alliances and the creation of collaborative advantage', Journal of Higher Education Policy and Management 35(2): 179-92.

Hanneman, R.A. and Riddle, M. (2005) Introduction to Social Network Methods, Riverside, CA: University of California.

Hüther, O. and Krücken, G. (2016) 'Nested Organizational Fields: Isomorphism and Differentiation Among European Universities', in E. Popp Berman and C. Paradeise (eds). The University under pressure (Volume 46), Bingley: Emerald, pp. 53-83.

Kmiotek-Meier, E., Karl, U. and Powell, J.J.W. (2020) 'Designing the (most) mobile university: The centrality of international student mobility in Luxembourg's higher education policy discourse', Higher Education Policy 33, 21-44. https://doi.org/10.1057/s41307-018-0118-4.

Knight, J. (2008) Joint and Double Degree Programmes: Vexing Questions and Issues, London: The Observatory on Borderless Higher Education.

Krücken, G. and Meier, F. (2006) 'Turning the University into an Organizational Actor', in G.S. Drori, J.W. Meyer and H. Hwang (eds). Globalization and Organization: World Society and Organizational Change, Oxford: Oxford University Press, pp. 241-257.

Kwiek, M. (2006) The University and the State, Frankfurt/Main: Peter Lang.

Lazega, E., Jourda, M-T., Mounier, L. and Stofer, R. (2008) 'Catching up with big fish in the big pond? Multi-level network analysis through linked design' Social Networks 30(2): 159-176.

Lévy, R. (2000) Implementing European Union Public Policy, Cheltenham: Edward Elgar.

Maassen, P. and Olsen, J.P. (2007) University Dynamics and European Integration, Dordrecht: Springer.

Marques, M. (2018) 'Research governance through public funding instruments: Institutional change of educational research in the European Union and England, 1984-2014', PhD dissertation, University of Luxembourg.

Mohrman, K., Ma, W. and Baker, D. (2008) 'The research university in transition: The emerging global model', Higher Education Policy 21(1): 5-27.

Mutch, A., Delbridge, R. and Ventresca, M. (2006) 'Situating organizational action: The relational sociology of organizations', Organization 13(5): 607-625.

Musselin, C. (2009) 'New Management Responsibilities: The Organizational Transformation of European Universities', in J.A. Douglass, C.J. King, and I. Feller (eds). Globalization's Muse: Universities and Higher Education Systems in a Changing World, Berkeley, CA: Public Policy Press, pp. 371-384.

Neave, G. (2005) On Snowballs, Slopes and the Process of Bologna: Some Testy Reflections on the Advance of Higher Education in Europe, Oslo: University of Oslo.

Obst, D., Kuder, M. and Banks, C. (2011) Joint and Double Degree Programs in the Global Context, New York: Institute of International Education.

Papatsiba, V. (2014) 'Policy goals of European integration and competitiveness in academic collaborations: An examination of Joint Master's and Erasmus Mundus Programmes', Higher Education Policy 27(1): 43-64.

Papatsiba, V. (2006) 'Making higher education more European through student mobility? Revisiting EU initiatives in the context of the Bologna Process', Comparative Education 42(1): 93-111.

Pépin, L. (2006) The History of European Cooperation in Education and Training, Luxembourg, Luxembourg: Office for Official Publications of the European Communities.

Powell, J.J.W., Bernhard, N. and Graf, L. (2012) 'The emergent European model in skill formation. Comparing higher education and vocational training in the Bologna and Copenhagen processes', Sociology of Education 85(3): 240-258.

Powell, J.J.W. and Finger, C. (2013) 'The Bologna process's model of mobility in Europe: The relationship of its spatial and social dimensions', European Educational Research Journal 12(2): $270-285$. 
Powell, W.W., White, D., Koput, K., and Owen-Smith, J. (2005) 'Network dynamics and field evolution: The growth of interorganizational collaboration in the life sciences', American Journal of Sociology 110(4): 1132-1205.

Prell, C. (2012) Social Network Analysis. History, Theory and Methodology, London: SAGE.

Risse, T. (2010) A Community of Europeans? Transnational Identities and Public Spheres, Ithaca, NY: Cornell University Press.

Rivza, B. and Teichler, U. (2007) 'The changing role of student mobility', Higher Education Policy 20(4): 457-475.

Sadecka, A. (2011) 'The Erasmus Mundus programme as a vehicle for development', Baltic Region 3: 94-98.

Serrano-Velarde, K. (2015)'Words into deeds: The use of framing strategy in EU higher education policy', Critical Policy Studies 9(1): 41-57.

Shields, R.A. (2013) 'Globalization and international student mobility: A network analysis', Comparative Education Review 57(4): 609-636.

Teichler, U. (2017) 'Internationalisation and trends in higher education and the changing role of international student mobility', Journal of International Mobility 5(1): 177-216.

Teichler, U. (ed) (2002) ERASMUS in the SOCRATES Programme - Findings of an Evaluation Study, Bonn, Germany: Lemmens.

Veiga, A. and Magalhães, A. (2017) 'Four 'I's Configuring European Higher Education Governance', in I. Bleiklie, J. Enders and B. Lepori (eds). Managing universities, London: Palgrave Macmillan, pp. 191-215.

Viseu, S. (2017) 'How Do Educational Researchers Organize Their Work? A Social Network Analysis on Co-authorship Relations', SAGE Research Methods Cases in Education. https://doi.org/10.4135/ 9781473998520.

Vukasovic, M. (2013) 'Change of higher education in response to European pressures: Conceptualization and operationalization of Europeanization of higher education', Higher Education 66(3): 311-324.

van der Wende, M. and Huisman, J. (2004) 'Europe', in J. Huisman and M. van der Wende (eds). On Cooperation and Competition, Bonn, Germany: Lemmens, pp. 17-50.

Watts, D.J. and Strogatz, S.H. (1998) 'Collective dynamics of 'small-world' networks', Nature 393: 440-442.

Yarosh, M., Lukic, D. and Santibáñez-Gruber, R. (2018) 'Intercultural competence for students in international joint master programmes', International Journal of Intercultural Relations 66: 52-72.

Zapp, M., Helgetun, J.B. and Powell, J.J.W. (2018) '(Re)shaping Educational Research through 'Programification': Institutional Expansion, Change, and Translation in Norway', European Journal of Education 53(2): 202-217.

Zapp, M., Marques, M. and Powell, J.J.W. (2018) European Educational Research (Re)constructed: Institutional Change in Germany, the United Kingdom, Norway, and the European Union, Oxford: Symposium Books.

Zapp, M. and Ramirez, F.O. (2019) 'Beyond isomorphism and internationalization. Towards a global higher education regime, Comparative Education 55(4): 473-493.

Publisher's Note Springer Nature remains neutral with regard to jurisdictional claims in published maps and institutional affiliations. 